

\title{
Hydration and Ionic Conductivity of Model Cation and Anion-Conducting Ionomers in Buffer Solutions (Phosphate, Acetate, Citrate)
}

\author{
L. Pasquini, O Wacrenier, M. L Di Vona, Philippe Knauth
}

\section{To cite this version:}

L. Pasquini, O Wacrenier, M. L Di Vona, Philippe Knauth. Hydration and Ionic Conductivity of Model Cation and Anion-Conducting Ionomers in Buffer Solutions (Phosphate, Acetate, Citrate). Journal of Physical Chemistry B, 2018, 122, pp.12009 - 12016. 10.1021/acs.jpcb.8b08622 . hal-03186996

\section{HAL Id: hal-03186996 \\ https://hal-amu.archives-ouvertes.fr/hal-03186996}

Submitted on 1 Apr 2021

HAL is a multi-disciplinary open access archive for the deposit and dissemination of scientific research documents, whether they are published or not. The documents may come from teaching and research institutions in France or abroad, or from public or private research centers.
L'archive ouverte pluridisciplinaire HAL, est destinée au dépôt et à la diffusion de documents scientifiques de niveau recherche, publiés ou non, émanant des établissements d'enseignement et de recherche français ou étrangers, des laboratoires publics ou privés. 


\title{
Hydration and Ionic Conductivity of Model Cation and Anion-Conducting Ionomers in Buffer Solutions (Phosphate, Acetate, Citrate)
}

L. Pasquini ${ }^{1,2}$, O. Wacrenier ${ }^{1}$, M. L. Di Vona ${ }^{2,3}$, P. Knauth ${ }^{1,2 *}$

1 Aix Marseille Univ, CNRS, MADIREL (UMR 7246), Campus Etoile-St Jérôme, 13013 Marseille, France

${ }^{2}$ International Associated Laboratory (L.I.A.) "Tonomer Materials for Energy", Aix Marseille Univ, CNRS, Univ. Rome Tor Vergata

${ }^{3}$ Univ. Rome Tor Vergata, Dip. Ing. Industriale, Via del Politecnico, 00133 Roma, Italy

\begin{abstract}
We studied the gravimetric and volumetric water uptake and ionic conductivity of two model ionomers, cation-conducting sulfonated poly(ether ether ketone) (SPEEK) and anion-conducting polysulfone-trimethylammonium chloride (PSU-TMA), after immersion in phosphate, acetate and citrate buffer solutions. The equilibrium swelling of SPEEK and PSU-TMA ionomer networks was determined as a function of $\mathrm{pH}$ and buffer composition. The hydration data can be interpreted using the osmotic swelling pressure dependence on the ion exchange capacity of the ionomers and the concentration of the electrolyte solutions. In the case of SPEEK, anisotropic swelling is observed in diluted buffer solutions, where the swelling pressure is higher. A large water uptake is observed for citrate ions, due to the large hydration of this bulky anion. The ionic conductivity is related to the conducting ions and, in the case of SPEEK, to sorbed excess electrolyte. The highest ionic conductivity is observed after immersion in phosphate buffers. Ionic cross-linking is for the first time observed in the case of an anion-conducting ionomer in presence of divalent citrate ions, which limits the volumetric swelling and decreases the ionic conductivity of PSU-TMA.
\end{abstract}

\footnotetext{
* Corresponding author: Philippe.Knauth@univ-amu.fr
} 


\section{Introduction}

Polyelectrolytes are macromolecules with ionic groups grafted on the main or side chains ${ }^{1,2}$. They are called ionomers, when a nanophase separation between hydrophobic and hydrophilic domains is observed with the formation of nanosized ion conduction channels inside the solid polymer matrix ${ }^{3}$. A well-defined nanophase separation promotes better-connected and less tortuous ion conduction channels and enhances the ionic conductivity ${ }^{4,5}$, but also the ionic permeability $^{6-8}$. The selectivity of the ion transport process can therefore be improved by a careful balance between hydrophilic and hydrophobic domains.

Ionomers are often used in membrane form for applications, typically prepared by casting from an appropriate solvent ${ }^{9,}{ }^{10}$. The hydrolytic stability ${ }^{11,12}$ is related to the amount of ion exchange groups (a high ion exchange capacity increases the hydrophilicity and generally the swelling and solubility in polar and protic solvents with high dielectric constant) and to the hydrophobicity of the ionomer backbone (which might increase the solubility in non-polar solvents).

One can prepare cation-conducting ionomers (including proton exchange membranes) by grafting various cation exchange groups, in the majority of cases sulfonic acid ${ }^{13-16}$, and anionconducting ionomers (including hydroxide exchange membranes) by anchoring typically quaternary ammonium groups ${ }^{17-20}$. The ionic conductivity is related to the ion exchange capacity of the polymers, but also to the solvation of the conducting ions and other factors such as the connectivity and tortuosity of the ion conduction channels in the ionomer ${ }^{21}$.

Ion exchange polymers have many important applications, including separation membranes for electrochemical energy technologies ${ }^{22,23}$, such as polymer electrolyte membrane fuel cells ${ }^{14,19,24}$ and redox flow batteries ${ }^{25,26}$, and other environmental technologies, such as water purification (by ultrafiltration ${ }^{27}$ or electrodialysis ${ }^{20,28}$ ). They have also important applications in the biological field, where ionomers can be practical models for protein membranes or other biochemical systems, in which ion transport plays a role.

In particular, biofuel cells ${ }^{29}$ and enzymatic fuel cells ${ }^{30}$ have recently been much improved and really promising performance jumps have been reported ${ }^{31}$. Biofuel cells work still mostly with liquid electrolytes, but a miniaturisation using ion exchange membrane separators is worthwhile to open the field of power supplies for miniaturized sensors and actuators and medical systems.

The used separator membranes should be biocompatible and should not alter the enzymatic activity. Nafion-type membranes are potentially harmful to the enzymatic activity due to the presence of fluorinated degradation species ${ }^{32}$. Membranes obtained with functionalized nonfluorinated organic polymers are a good alternative, thanks to their ion selectivity, high ionic 
conductivity, good stability, long life and low production cost, while keeping a low overall size to tend towards the miniaturization of the device.

Enzymatic fuel cells ${ }^{30}$ work typically in $\mathrm{pH}$-buffered media in order to keep a good enzymatic activity without enzyme denaturation; phosphate, citrate and acetate buffers are the most commonly applied. However, the hydration stability and conductivity of ion exchange membranes in these solutions has never been studied. The hydration behaviour of ion exchange membranes is governed by the interplay between the osmotic pressure of inner and outer electrolyte solutions and the mechanical properties of the membrane, which are interdependent ${ }^{11}$, ${ }^{33-36}$. We have previously reported a simple phenomenological model, relating the hydration and the mechanical properties of ionomers ${ }^{35}$. The ionic conductivity is also very sensitive to the hydration, because the ion mobility is a function of the amount of water ${ }^{21,37}$. The effects of $\mathrm{pH}$ and ionic strength on the swelling of polyelectrolyte ${ }^{38,39}$ and copolymer gels ${ }^{33}$ were studied before.

In the following, we report for the first time the hydration and ionic conductivity after immersion in phosphate, citrate and acetate buffers of two model ionomers: cation-conducting sulfonated poly(ether ether ketone) (SPEEK) $)^{40-43}$ and anion-conducting PSU-trimethylammonium chloride (PSU-TMA) $44-48$ (Figure 1). These ionomers are among the most investigated and can be applied in enzymatic and biofuel cells. Sufficient literature exists for both ionomers ${ }^{20,24,43}$, reporting many relevant properties and data facilitating the discussion of the measured properties.

We studied $0.05 \mathrm{M}$ and $0.1 \mathrm{M}$ solutions of phosphate, citrate and acetate buffers, which are the most employed in enzymatic fuel cells. The hydration and ionic conductivity of SPEEK and PSU-TMA ionomer networks were determined as a function of $\mathrm{pH}$ and buffer composition.<smiles>COc1ccc(Oc2ccc(C(=O)c3ccc(C)cc3)cc2)c(S(=O)(=O)O)c1</smiles><smiles>COc1ccc(C(C)(C)c2ccc(Oc3ccc(S(=O)(=O)c4ccc(C)cc4)cc3)c(C[N+](C)(C)C)c2)cc1</smiles> 
Figure 1. Repeat units of SPEEK and PSU-TMA.

\section{Experimental}

SPEEK was prepared by reaction of poly(ether ether ketone) (PEEK, Victrex) with concentrated sulphuric acid ${ }^{49}$. The degree of sulfonation of SPEEK, determined by NMR spectroscopy and acid-base titration ${ }^{15,50}$, was DS $=0.96$, corresponding to an ion exchange capacity IEC $=2.62$ meq $\mathrm{g}^{-1}$. The membranes were cast from DMSO solutions using a doctor-blade equipment. $1 \mathrm{~g}$ SPEEK was dissolved in $30 \mathrm{~mL}$ DMSO. After evaporation to around one third of the original volume, the solution was spread on a glass plate using a doctor-blade type equipment and then put in the oven at $120^{\circ} \mathrm{C}$ for $24 \mathrm{~h}$. The dry density of the ionomer in acid form is $1.3 \mathrm{~g} \mathrm{~cm}^{-335,51}$. PSU-TMA was prepared by chloromethylation of PSU using the procedure reported in reference ${ }^{46}$. The chloromethylated product was then aminated by reaction with trimethylamine ${ }^{44}$. The degree of amination determined by NMR spectroscopy and acid-base titration was DAM $=0.66$, corresponding to an ion exchange capacity IEC $=1.34 \mathrm{meq}^{-1}$. The membranes were cast from DMSO solutions; typically, $10 \mathrm{~mL}$ of a $0.05 \mathrm{M}$ solution of PSU-TMA was evaporated to $5 \mathrm{~mL}$, cast on a Petri dish then heated to dryness at $100{ }^{\circ} \mathrm{C}$ for $24 \mathrm{~h}$.

The dry density of the ionomer in $\mathrm{Cl}$ form was measured after drying the membranes over $\mathrm{P}_{2} \mathrm{O}_{5}$ for $24 \mathrm{~h}$. The membranes were rapidly weighed in a closed vessel and the geometrical dimensions determined. The average value of 9 measurements was $(1.15 \pm 0.05) \mathrm{g} \mathrm{cm}^{-3}$.

The hydration and ion conductivity was investigated in 3 different buffers: phosphate $\left(\mathrm{H}_{2} \mathrm{PO}_{4}^{-}\right.$ $\left./ \mathrm{HPO}_{4}{ }^{2-}\right)$, citrate (monocitrate/dicitrate) and acetate $\left(\mathrm{CH}_{3} \mathrm{CO}_{2} \mathrm{H} / \mathrm{CH}_{3} \mathrm{CO}_{2}{ }^{-}\right)$. The concentration of the buffer solutions was 0.1 or $0.05 \mathrm{M}$. The desired $\mathrm{pH}$ values were obtained by mixing the buffer components and the $\mathrm{pH}$ was determined with a calibrated $\mathrm{pH}$ meter (Mettler Toledo).

The membranes were immersed in $100 \mathrm{~mL}$ buffer solution for $24 \mathrm{~h}$ at room temperature, washed rapidly in pure water to remove any excess of buffer solutions and wiped carefully with absorbing paper before the measurements.

The gravimetric water uptake $W U$ was measured in duplicate at $25{ }^{\circ} \mathrm{C}$ and calculated according to the equation:

$$
W U=100 \cdot \frac{\left(m_{w e t}-m_{d r y}\right)}{m_{d r y}}
$$

The mass of wet samples $\left(\mathrm{m}_{\text {wet }}\right)$ was determined after $24 \mathrm{~h}$ immersion in buffer solutions. The mass of dry samples $\left(\mathrm{m}_{\text {dry }}\right)$ was measured in a closed vessel after drying over $\mathrm{P}_{2} \mathrm{O}_{5}$ for $24 \mathrm{~h}$. 
Furthermore, the variations of sample area and thickness were determined after immersion in buffers by measuring the sample dimensions with a micrometer (Mitutoyo 293-230). The dry samples had an area of around $4 \mathrm{~cm}^{2}$ and a thickness between 20 and $40 \mu \mathrm{m}$. The percentage variations of area $(\Delta A)$ and thickness $(\Delta d)$ were calculated from the relations:

$$
\Delta A=100 \cdot \frac{A_{w e t}-A_{d r y}}{A_{d r y}} \quad \Delta d=100 \cdot \frac{d_{w e t}-d_{d r y}}{d_{d r y}}
$$

The density $D$ of the ionomer after swelling can be obtained from the following equation:

$$
D=\frac{m_{w e t}}{A_{w e t} \cdot d_{w e t}}
$$

The through-plane ionic conductivity was measured by impedance spectrometry between $1 \mathrm{~Hz}$ and $6 \mathrm{MHz}$ using an impedance spectrometer Biologic VSP300. The amplitude of the oscillating voltage was $20 \mathrm{mV}$. The samples were studied at $25{ }^{\circ} \mathrm{C}$ in fully humidified conditions inside a Swagelok cell with two stainless steel electrodes. The sample resistance $R_{S}$ was obtained from typical impedance spectra (Figure 2) using the intercept with the real axis. The ionic conductivity $\sigma$ was calculated using the equation:

$$
\sigma=\frac{d_{w e t}}{R_{s} \cdot A_{w e t}}
$$

\section{Results}

The gravimetric and volumetric water uptake, the change of membrane dimensions (area and thickness), the density and the ionic conductivity of SPEEK and PSU-TMA membranes after immersion in phosphate, citrate or acetate buffers at various $\mathrm{pH}$ values at $25{ }^{\circ} \mathrm{C}$ are reported in Tables 1 and 2, respectively. Typical impedance spectra for SPEEK and PSU-TMA membranes are shown in Figure 2. The ionic conductivities $\sigma$, calculated according to equation 4, are reported in Tables 1 and 2. 


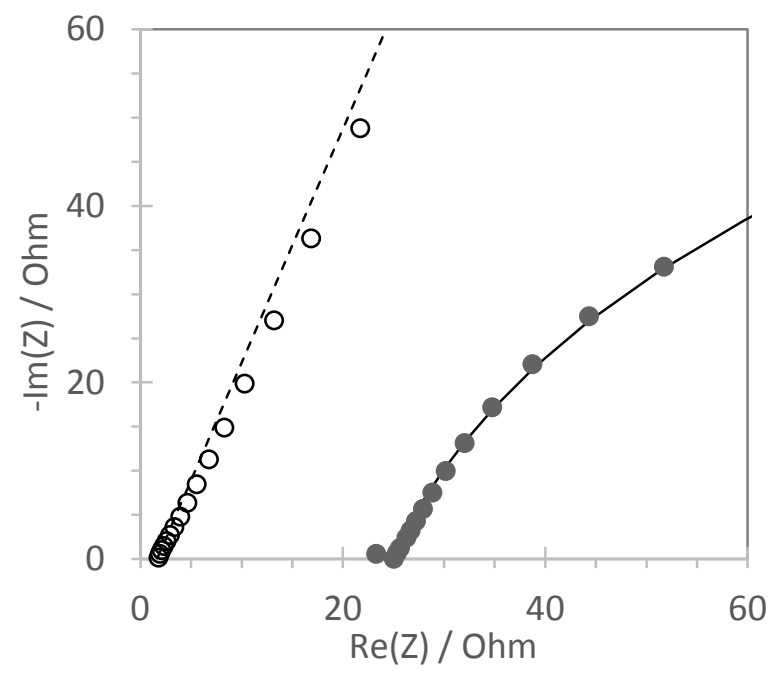

Figure 2. Typical impedance spectra observed for SPEEK (open dots, $R_{S}=1.6 \Omega$, thickness $d=$ $25 \mu \mathrm{m}$ ) and PSU-TMA (black dots, $\mathrm{R}_{\mathrm{S}}=24.8 \Omega, \mathrm{d}=40 \mu \mathrm{m}$ ) membranes at $25^{\circ} \mathrm{C}$ after immersion in phosphate buffer at $\mathrm{pH}=5.8$. The lines represent non-linear least-square plots using an equivalent circuit consisting of a series arrangement of $\mathrm{R}_{\mathrm{S}}$ and a parallel circuit resistance//constant phase element. ${ }^{52,53}$ 
Table 1. Gravimetric $(W U)$ and volumetric $(\Delta V)$ water uptake, change of membrane area $\Delta A$ and thickness $\Delta d$, density $D$ and ionic conductivity $\sigma$ of SPEEK in various buffers and $\mathrm{pH}$ at 25 ${ }^{\circ} \mathrm{C}$. The molar counter-ion concentration $\mathrm{c}^{\prime}\left(\mathrm{Na}^{+}\right)$in each buffer solution was calculated from the acid and base concentrations determined using equation (8). Sample dissolution is indicated by " /".

\begin{tabular}{|c|c|c|c|c|c|c|c|c|c|}
\hline $\mathbf{0 . 1} \mathbf{M}$ & \multicolumn{3}{|c|}{ Phosphate } & \multicolumn{3}{c|}{ Citrate } & \multicolumn{3}{c|}{ Acetate } \\
\hline $\mathbf{p H}$ & $\mathbf{5 . 8}$ & $\mathbf{7}$ & $\mathbf{8}$ & $\mathbf{4}$ & $\mathbf{5}$ & $\mathbf{5 . 9}$ & $\mathbf{3 . 6}$ & $\mathbf{4 . 4}$ & $\mathbf{5}$ \\
\hline$W U / \%$ & 26.7 & 32.3 & 27.2 & 76.0 & 65.7 & 63.3 & $/$ & 203.0 & 66.7 \\
\hline$\Delta V / \%$ & 33.3 & 41.8 & 37.8 & 139.6 & 105.0 & 105.9 & $/$ & 293.6 & 77.8 \\
\hline$\Delta A / \%$ & 15.0 & 21.3 & 27.0 & 80.1 & 60.3 & 62.5 & $/$ & 136.4 & 51.2 \\
\hline$\Delta d / \%$ & 15.3 & 16.9 & 11.9 & 34.4 & 26.7 & 27.9 & $/$ & 66.5 & 17.9 \\
\hline$D / \mathrm{g} \mathrm{cm}^{-3}$ & 1.09 & 1.22 & 1.22 & 0.92 & 0.90 & 0.92 & $/$ & 1.05 & 1.06 \\
\hline$\sigma / \mathrm{mS} \mathrm{cm}^{-1}$ & 5.6 & 6.5 & 8.4 & 1.6 & 4.1 & 3.8 & $/$ & $/$ & 4.5 \\
\hline $\mathrm{c}^{\prime}\left(\mathrm{Na}^{+}\right) / \mathrm{molL}^{-1}$ & 0.104 & 0.139 & 0.186 & 0.115 & 0.163 & 0.193 & 0.006 & 0.029 & 0.063 \\
\hline $\mathbf{0 . 0 5} \mathbf{M}$ & & & & & & & & & \\
\hline$W U / \%$ & 66.0 & 63.0 & 65.3 & 77.7 & 72.4 & 66.3 & $/$ & $/$ & $/$ \\
\hline$\Delta V / \%$ & 76.0 & 70.7 & 93.0 & 90.0 & 68.7 & 66.1 & $/$ & $/$ & $/$ \\
\hline$\Delta A / \%$ & 56.1 & 51.8 & 65.3 & 62.9 & 53.8 & 51.5 & $/$ & $/$ & $/$ \\
\hline$\Delta d / \%$ & 12.6 & 12.4 & 16.8 & 16,7 & 10.5 & 9.6 & $/$ & $/$ & $/$ \\
\hline$D / \mathrm{g} \mathrm{cm}^{-3}$ & 1.26 & 1.16 & 1.09 & 1.18 & 1.12 & 1.18 & $/$ & $/$ & $/$ \\
\hline$\sigma / \mathrm{mS} \mathrm{cm}$ & 6.6 & 6.6 & 8.3 & - & - & - & $/$ & $/$ & $/$ \\
\hline $\mathrm{c}^{\prime}\left(\mathrm{Na}^{+}\right) / \mathrm{molL}^{-1}$ & 0.052 & 0.069 & 0.093 & 0.057 & 0.082 & 0.096 & 0.003 & 0.014 & 0.031 \\
\hline
\end{tabular}


Table 2. Gravimetric ( $W U$ ) and volumetric $(\Delta V)$ water uptake, change of membrane area $\Delta A$ and thickness $\Delta d$, density $D$ and ionic conductivity $\sigma$ of PSU-TMA in various buffers and $\mathrm{pH}$ at $25{ }^{\circ} \mathrm{C}$. The molar concentrations of the monovalent $\mathrm{c}^{\prime}\left(\mathrm{A}^{-}\right)$and divalent $\mathrm{c}^{\prime}\left(\mathrm{A}^{2-}\right)$ counter-anions in each buffer solution are calculated using equation (8).

\begin{tabular}{|c|c|c|c|c|c|c|c|c|c|}
\hline $\mathbf{0 . 1} \mathbf{M}$ & \multicolumn{3}{|c|}{ Phosphate } & \multicolumn{3}{c|}{ Citrate } & \multicolumn{3}{c|}{ Acetate } \\
\hline $\mathbf{p H}$ & $\mathbf{5 . 8}$ & $\mathbf{7}$ & $\mathbf{8}$ & $\mathbf{4}$ & $\mathbf{5}$ & $\mathbf{5 . 9}$ & $\mathbf{3 . 6}$ & $\mathbf{4 . 4}$ & $\mathbf{5}$ \\
\hline$W U / \%$ & 11.5 & 14.0 & 17.0 & 24.1 & 22.7 & 10.0 & 19.8 & 10.4 & 10.7 \\
\hline$\Delta V / \%$ & 17.1 & 25.1 & 28.1 & 16.5 & 22.1 & 8.8 & 24.8 & 31.9 & 22.5 \\
\hline$\Delta A / \%$ & 11.6 & 11.5 & 12.7 & 6.5 & 6.4 & 7.5 & 10 & 10.8 & 12.5 \\
\hline$\Delta d / \%$ & 4.9 & 12.1 & 13.6 & 9.4 & 14.4 & 1.0 & 13.2 & 19.2 & 8.7 \\
\hline$D / \mathrm{g} \mathrm{cm}^{-3}$ & 0.97 & 1.02 & 1.03 & 1.14 & 1.11 & 1.07 & 0.85 & 0.91 & 1.00 \\
\hline$\sigma / \mathrm{mS} \mathrm{cm}^{-1}$ & 0.6 & 1.0 & 1.3 & $<0.01$ & 0.01 & $<0.01$ & 1.0 & 1.1 & 0.9 \\
\hline $\mathrm{c}^{\prime}(\mathrm{A}) / \mathrm{mol} \mathrm{L}^{-1}$ & 0.096 & 0.061 & 0.014 & 0.085 & 0.037 & 0.007 & 0.006 & 0.029 & 0.063 \\
\hline $\mathrm{c}^{\prime}\left(\mathrm{A}^{2-}\right) / \mathrm{mol} \mathrm{L}^{-1}$ & 0.004 & 0.039 & 0.086 & 0.015 & 0.063 & 0.093 & - & - & - \\
\hline $\mathbf{0 . 0 5} \mathbf{M}$ & & & & & & & & & \\
\hline$W U / \%$ & 6.1 & 9.1 & 23.3 & 19.7 & 12.0 & 11.7 & - & - & - \\
\hline$\Delta V / \%$ & 30.9 & 19.3 & 23.2 & 5.5 & 9.4 & 8.8 & - & - & - \\
\hline$\Delta A / \%$ & 24.4 & 13.8 & 13.8 & 5.2 & 6.3 & 7.5 & - & - & - \\
\hline$\Delta d / \%$ & 5.3 & 4.8 & 8.2 & 0.3 & 2.8 & 1.0 & - & - & - \\
\hline$D / \mathrm{g} \mathrm{cm}^{-3}$ & 0.93 & 1.08 & 1.13 & 1.21 & 1.13 & 1.09 & - & - & - \\
\hline$\sigma / \mathrm{mS} \mathrm{cm}^{-1}$ & 0.20 & 0.29 & 0.32 & $<0.01$ & $<0.01$ & $<0.01$ & - & - & - \\
\hline $\mathrm{c}^{\prime}(\mathrm{A}) / \mathrm{mol} \mathrm{L}^{-1}$ & 0.048 & 0.031 & 0.007 & 0.042 & 0.018 & 0.004 & - & - & - \\
\hline $\mathrm{c}^{\prime}\left(\mathrm{A}^{2-}\right) / \mathrm{mol} \mathrm{L}^{-1}$ & 0.002 & 0.019 & 0.043 & 0.008 & 0.032 & 0.046 & - & - & - \\
\hline
\end{tabular}




\section{Discussion}

Theory: buffer equilibria, counter-ion concentration and osmotic pressure

For the $\mathrm{H}_{2} \mathrm{PO}_{4}^{-} / \mathrm{HPO}_{4}^{2-}$ buffer, $\mathrm{pKa}=7.20$ at $25^{\circ} \mathrm{C}$, the equilibrium can be written:

$$
\mathrm{H}_{2} \mathrm{PO}_{4}^{-}+\mathrm{H}_{2} \mathrm{O} \rightleftarrows \mathrm{HPO}_{4}^{2-}+\mathrm{H}_{3} \mathrm{O}^{+}
$$

Acetic acid is a weak acid with a $\mathrm{pKa}=4.76$ at $25^{\circ} \mathrm{C}$; the acid dissociation is small and the concentration of hydronium ions can be neglected for the calculation of the osmotic pressure.

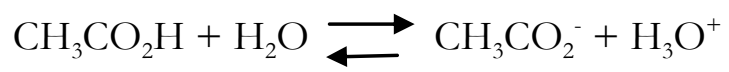

Citric acid is a tribasic acid; the buffer prepared corresponds to the second dissociation step, coincidentally also with $\mathrm{pKa}=4.76$ at $25^{\circ} \mathrm{C}$.

$$
-\mathrm{O}_{2} \mathrm{C}(\mathrm{HO}) \mathrm{C}\left(\mathrm{CH}_{2} \mathrm{CO}_{2} \mathrm{H}\right)_{2}+\mathrm{H}_{2} \mathrm{O} \rightleftarrows \mathrm{O}_{2} \mathrm{C}(\mathrm{HO}) \mathrm{C}\left(\mathrm{CH}_{2} \mathrm{CO}_{2} \mathrm{H}\right) \mathrm{CH}_{2} \mathrm{CO}_{2}{ }^{-}+\mathrm{H}_{3} \mathrm{O}^{+}
$$

The concentrations of the acidic form $\mathrm{c}(\mathrm{HA})$ and of the basic form $\mathrm{c}(\mathrm{A})$ in the buffer can be calculated at each $\mathrm{pH}$ according to the well-known Henderson-Hasselbalch equation ${ }^{54}$ :

$$
p H=p K a+\log \frac{c(A)}{c(H A)}
$$

In this equation, $p K a$ is the negative decadic logarithm of the acid constant. The $\mathrm{Na}^{+}$ion concentrations in Table 1 are obtained by a straightforward calculation. .

The osmotic pressure of electrolytic solutions is proportional to the solute activities (or solute concentrations for ideal solutions). The swelling of polyelectrolytes is proportional to the osmotic pressure difference; the relation between the osmotic swelling pressure $\pi$ and the counter ion concentrations inside the ionomer $c(i)$ and in the buffer solution $c^{\prime}(i)$ is given by the following equation ${ }^{33}$ :

$$
\pi=R T \sum_{i} c(i)-c^{\prime}(i)
$$

$R$ is the ideal gas constant and $T$ the absolute temperature. The counter-ions are $\mathrm{Na}^{+}$ions for cation-conducting SPEEK and for anion-conducting PSU-TMA: $\mathrm{H}_{2} \mathrm{PO}_{4}^{-} / \mathrm{HPO}_{4}^{2-}, \mathrm{CH}_{3} \mathrm{CO}_{2}^{-}$or $\mathrm{O}_{2} \mathrm{C}(\mathrm{HO}) \mathrm{C}\left(\mathrm{CH}_{2} \mathrm{CO}_{2} \mathrm{H}\right)_{2} / \mathrm{O}_{2} \mathrm{C}(\mathrm{HO}) \mathrm{C}\left(\mathrm{CH}_{2} \mathrm{CO}_{2} \mathrm{H}\right) \mathrm{CH}_{2} \mathrm{CO}_{2}{ }^{-}$in phosphate, acetate and citrate buffers respectively.

The counter-ion concentration inside the ionomer can be calculated from the ion exchange capacity and the dry density of the ionomers. For SPEEK, the dry density was determined before $\left(1.3 \mathrm{~g} \mathrm{~cm}^{-3}{ }^{35,51}\right)$ and for PSU-TMA, the average value from 9 measurements was $(1.15 \pm 0.05) \mathrm{g}$ $\mathrm{cm}^{-3}$. This gives molar counter-ion concentrations of $3.41 \mathrm{~mol} \mathrm{~L}^{-1}$ and $1.47 \mathrm{~mol} \mathrm{~L}^{-1}$ for SPEEK and PSU-TMA, respectively. 
Gravimetric (WU) and volumetric $(\Delta V)$ water uptake of SPEEK and PSU-TMA

Given the molar counter-ion concentrations inside SPEEK and PSU-TMA, the osmotic swelling pressure is more than double for SPEEK than for PSU-TMA according to equation (9). Consequently, the $W U$ and $\Delta V$ values for similar buffer concentrations are much larger for SPEEK than for PSU-TMA. Whereas in $0.1 \mathrm{M}$ solutions, $W U$ is about double for SPEEK in comparison with PSU-TMA in phosphate buffer, it is about triple for citrate and an even larger difference is observed for acetate. In all cases, except PSU-TMA in citrate buffers (see below), the volumetric swelling $\Delta V$ is larger than the gravimetric $W U$, showing that the membrane loses stiffness, due to the presence of the plastifying solvent.

Within a type of buffer, $W U$ and $\Delta V$ can be correlated with the osmotic swelling pressure at a certain $\mathrm{pH}$. For SPEEK in acetate buffers, the membrane dissolves totally at the most acidic $\mathrm{pH}$ where the counter-ion concentration is particularly low (acetic acid presents a low dissociation). In phosphate buffers, the WU is lower, due to the larger counter-ion concentrations in the outer solution, which contains a mixture of hydrogen- and dihydrogen-phosphate. According to the expectation, the WU is approximately double in $0.05 \mathrm{M}$ phosphate buffer, due to the lower outer solution concentration leading to a larger osmotic swelling pressure. Intermediate data are observed in citrate buffer; evidently, some citrate co-ions are adsorbed by the ionomer and the large, strongly hydrated citrate ions drag supplementary water molecules. WU decreases with increasing counter-ion concentration in the citrate buffer solution. The increase of $W U$ is lower than expected in the $0.05 \mathrm{M}$ citrate buffer, because there is less driving force for co-ion adsorption from the more diluted solution.

For PSU-TMA, $W U$ is generally much lower due to the lower IEC, which decreases the osmotic swelling pressure of PSU-TMA, especially in the acetate buffer. Furthermore, the difference between 0.1 and $0.05 \mathrm{M}$ solutions is much lower than in the case of SPEEK, because the swelling pressure is much lower. One must also take into account the fact that divalent anions, present in phosphate and citrate buffers, are highly hydrated, due to the larger charge and increase $W U$.

For acetate buffers, one can clearly observe that an increase of the counter-ion concentration leads to a decrease of $W U$. The trend is opposite for phosphate buffers, due to an increasing concentration of divalent hydrogen phosphate ions with increase of $\mathrm{pH}$. The case of citrate buffers is particular: it is the only buffer, where $\Delta V$ is consistently lower than $W U$. WU decreases with increasing counter-ion concentrations in the outer solution, because the amount of divalent ions increases. Furthermore, WU is nearly similar, or even decreases, in the $0.05 \mathrm{M}$ buffer. These 
surprising facts can be related to an ionic cross-linking mechanism by divalent citrate ions that is discussed below.

Variations of membrane area $(\Delta A)$, thickness $(\Delta d)$ and density $(D)$

Tables 1 and 2 show the area and thickness variations for SPEEK and PSU-TMA, respectively. One notices globally much larger variations for SPEEK than for PSU-TMA, in agreement with the larger gravimetric water uptake, particularly in the case of the citrate buffer, as discussed below in more detail.

Considering SPEEK, it is remarkable that while the area and thickness variations are consistent in the $0.1 \mathrm{M}$ buffer solutions, the thickness variation is much smaller than the area variation in the $0.05 \mathrm{M}$ buffers (Table 1). The hydration is anisotropic in these cases, probably due to the larger swelling pressure in the diluted solution.

An anisotropic swelling behaviour of proton-conducting membranes has been demonstrated before. Alberti and coworkers reported the formation of oriented chain arrangements in constrained Nafion, leading to a strongly anisotropic swelling and proton conductivity, but these layered phases were formed under uniaxial pressure and with pure water ${ }^{55}$. Here, the swelling occurs without constraints, but it is clearly anisotropic in diluted buffers $(0.05 \mathrm{M})$, which can be attributed to an initial orientation of uncross-linked SPEEK chains. This observation is of interest for the optimization of swelling and conductivity in SPEEK ${ }^{56}$.

The density of wet SPEEK has an average value of $(1.15 \pm 0.05) \mathrm{g} \mathrm{cm}^{-3}$ (Table 1) with the noticeable exception of samples immersed in $0.1 \mathrm{M}$ citrate buffer, where the density is much lower. The most plausible explanation is that some adsorbed bulky citrate ions can enter the channels and expand their size, leading to a larger volume change. In the more diluted $0.05 \mathrm{M}$ solution, this effect is not observed, because the adsorption of excess electrolyte decreases with decreasing concentration of the external solution, in agreement with the previous discussion.

In PSU-TMA, the WU and the change of membrane dimensions (area and thickness) are quite similar within the experimental uncertainty in phosphate and acetate buffers. One can conclude that there is no anisotropic swelling and that preferred chain orientations do not exist in PSUTMA, but the volumetric swelling is always higher than the gravimetric water uptake, with the remarkable exception of citrate buffers. Here, $\Delta V$ is actually lower than $W U$. The average density is also higher than for the other samples. This singularity can be attributed to the presence of bulky doubly charged citrate counter-anions that permit an ionic cross-linking of macromolecular chains as shown schematically in Figure 3. This mechanism limits the volumetric swelling of the 
ionomer, because the chains are held together by electrostatic forces. This hypothesis is corroborated by the extremely low ionic conductivity of PSU-TMA in citrate solutions (Table 2), because the citrate ions are trapped inside the ionomer by this mechanism (see below). Ionic cross-linking has previously been reported for cationic-conducting ionomers ${ }^{57}$. To our knowledge, this is the first time that ionic cross-linking by anions is reported. One might ask why ionic cross-linking is not observed in the case of $\mathrm{HPO}_{4}{ }^{2-}$ anions; however, the anion size is also important, because the ion-ion interactions decrease strongly with the distance and the citrate ion is much bulkier than hydrogen-phosphate, which does not allow a sufficient proximity with the ionomer chains.
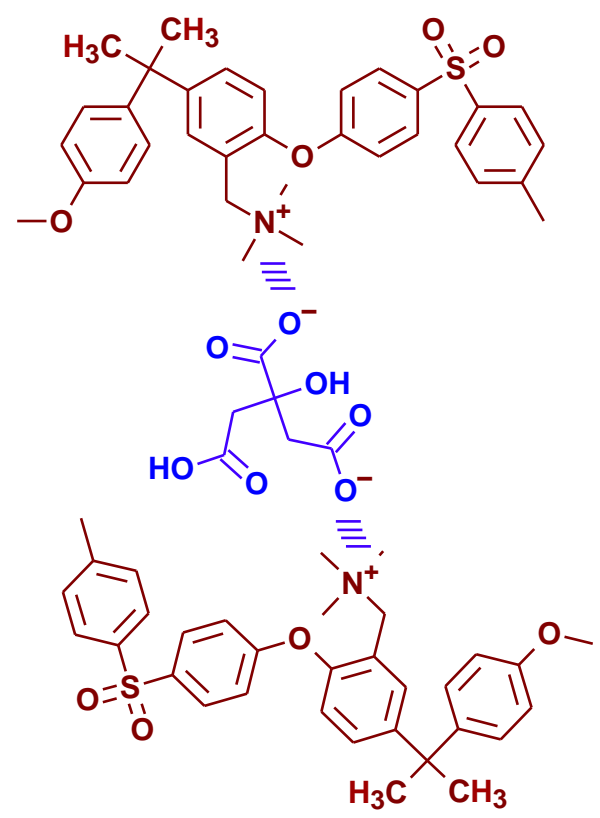

Figure 3. Schematic anionic crosslinking of PSU-TMA by dicitrate ions.

Ionic conductivity of SPEEK and PSU-TMA as function of bydration and conducting ions

In an ionomer, the ionic conductivity is due to the mobile counter-ions; the grafted ionic groups do not contribute. However, a contribution by excess ions adsorbed from the outer solution can play a role especially when the outer electrolyte solution is concentrated ${ }^{58}$.

The ionic conductivity is proportional to the concentration, mobility $u(i)$ and charge $q(i)$ of the mobile ions according to the well-known equation ${ }^{54}$ :

$$
\sigma=\sum_{i} q(i) \cdot u(i) \cdot c(i)
$$


A comparison of the ionic conductivity data reported in Tables 1 and 2 shows a much higher ionic conductivity of SPEEK vs PSU-TMA, which is evidently related to the more than double IEC of SPEEK, giving a more than twice higher mobile counter-ion concentration. Furthermore, the mobility of $\mathrm{Na}^{+}$ions, which exchange the protons initially present in SPEEK, is higher than that of the mobile anions in PSU-TMA, but it is much lower than that of very mobile protons that can move by structural diffusion (Grotthuss mechanism). In accordance with this fact, the ionic conductivity is between 2 and $8 \mathrm{mS} / \mathrm{cm}$, lower than for proton-conducting SPEEK ${ }^{37,49}$, due to the lower mobility of sodium ions in comparison with protons. The anion conductivity of PSU-TMA is between 0.2 and $1.3 \mathrm{mS} / \mathrm{cm}$, except for citrate buffers, where the doubly charged citrate anion can form ionic cross-links and have a very low mobility.

Other subtle variations can also be observed. For example, there is a good correlation between the ionic conductivity of SPEEK and the concentration of the buffer. This correlation indicates a contribution of excess sorbed ions to the total ionic conductivity. In SPEEK with a high IEC, adsorbed ions cannot be removed by washing, because the membranes dissolve in pure water. Furthermore, there is an influence of the ion charge, because the amount of doubly charged $\mathrm{HPO}_{4}^{2-}$ ions increases with increasing $\mathrm{pH}$, which gives a larger conductivity contribution due to larger adsorption. A similar observation can be made for the citrate buffer, where the concentration of doubly charged citrate ions increases with the $\mathrm{pH}$. In acetate buffers at lower $\mathrm{pH}$, where the concentration of $\mathrm{Na}^{+}$ions is very low, the SPEEK membrane swells very strongly and even dissolves, so that the conductivity measurement is impossible.

Other factors, such as a different level of hydration, play also a role. We have previously shown for SPEEK the possibility to increase the ion conductivity by increasing the hydration level, due to the mobility increase at high dilution ${ }^{49}$. In proton-conducting ionomers, this mobility change with hydration is well-known and attributed to the change of conduction mechanism with a higher contribution of structural diffusion vs vehicular diffusion ${ }^{59,}{ }^{60}$. Other factors such as a better connectivity of the ion-conduction channels and a better dissociation of ion pairs can also be operational. In fact, the conductivity of SPEEK in $0.05 \mathrm{M}$ phosphate buffer is identical or even higher than in $0.1 \mathrm{M}$ solutions, evidently due to a higher WU. In this case, the $\mathrm{pH}$ dependence is also lower, probably due to a lower sorption of ions from the more diluted buffer solution.

The consistently lower ionic conductivity of PSU-TMA membranes is related to the lower IEC and the lower anion mobility. Furthermore, the membranes were washed in water before the measurements, because they do not swell excessively, so that an important influence of excess ions sorbed from the buffer solution can be excluded here. The relatively high conductivity of 
acetate anions in PSU-TMA is in good agreement with the previously reported value ${ }^{61}$. Given the generally low values of $W U$, the improvement of ionic conductivity in $0.05 \mathrm{M}$ solution observed for SPEEK, is not detected in PSU-TMA.

The extremely low ionic conductivity determined for PSU-TMA in citrate buffer is consistent with an ionic crosslinking by the divalent citrate ions, which are therefore trapped inside the ionomer and have an extremely low mobility (Figure 3).

\section{Conclusions}

This work shows the importance of ion concentrations for the hydration and conductivity behaviour of ionomer membranes. An increasing concentration of ions in buffer solutions reduces the gravimetric water uptake. A simple interpretation of the hydration data can be based on the osmotic pressure dependence. The area and thickness variations show that for SPEEK in diluted buffer solutions, where the swelling pressure is higher, the variation of dimensions is larger in the plane than in the transverse direction. This anisotropy might be related to a preorientation of the chains. In PSU-TMA, the volumetric water uptake is larger than the gravimetric one, except in citrate buffer; this result is attributed to an ionic cross-linking by the bulky citrate di-anion, which reduces the volumetric swelling. The ionic conductivity confirms this ion-specific effect, because the ionic conductivity of the anion-conducting membrane is very low in citrate buffer.

A good compromise between low swelling and relatively high ionic conductivity is found in phosphate buffers, which seem most appropriate for use in enzymatic fuel systems.

\section{Acknowledgments}

The financial support of CNRS in the frame of the exploratory project "IMPEC" is gratefully acknowledged.

\section{References}

1. Manning, G. S., Counterion Binding in Polyelectrolyte Theory. Acc. Chem. Res. 1979, 12 (12), 443449.

2. $\quad$ Hess, M.; Jones, R. G.; Kahovec, J.; Kitayama, T.; Kratochvil, P.; Kubisa, P.; Mormann, W.; Stepto, R. F. T.; Tabak, D.; Vohlidal, J.; Wilks, E. S., Terminology of Polymers Containing Ionizable or Ionic Groups and of Polymers Containing Ions - (IUPAC Recommendations 2006). Pure Appl. Chemi. 2006, 78 (11), 2067-2074.

3. Kreuer, K. D.; Portale, G., A Critical Revision of the Nano-Morphology of Proton Conducting Ionomers and Polyelectrolytes for Fuel Cell Applications. Adv. Funct. Mater. 2013, 23 (43), 5390-5397. 
4. Eastman, S. A.; Kim, S.; Page, K. A.; Rowe, B. W.; Kong, S. H.; Soles, C. L., Effect of Confinement on Structure, Water Solubility, and Water Transport in Nafion Thin Films. Macromolecules 2012, 45 (19), 7920-7930.

5. Wu, L.; Zhang, Z. H.; Ran, J.; Zhou, D.; Li, C. R.; Xu, T. W., Advances In Proton-Exchange Membranes for Fuel Cells: An Overview on Proton Conductive Channels (PCCs). PhysChemChemPhys 2013, 15 (14), 4870-4887.

6. $\quad$ Knauth, P.; Pasquini, L.; Di Vona, M. L., Comparative Study of the Cation Permeability of Protonic, Anionic and Ampholytic Membranes. Solid State Ionics 2017, 300, 97-105.

7. $\quad$ Narducci, R.; Pasquini, L.; Chailan, J. F.; Knauth, P.; Di Vona, M. L., Low-Permeability Poly(Ether Ether Ketone)-Based Ampholytic Membranes. ChemPlusChem 2016, 81 (6), 550-556.

8. Doan, T. N. L.; Hoang, T. K. A.; Chen, P., Recent Development of Polymer Membranes as Separators For All-Vanadium Redox Flow Batteries. RSC Advances 2015, 5 (89), 72805-72815.

9. Kerres, J. A., Development of Ionomer Membranes for Fuel Cells. J. Membrane Sci. 2001, 185 (1), 3-27.

10. Kerres, J.; Cui, W.; Disson, R.; Neubrand, W., Development And Characterization Of Crosslinked Ionomer Membranes Based Upon Sulfinated and Sulfonated PSU - Crosslinked PSU Blend Membranes By Disproportionation Of Sulfinic Acid Groups. J. Membrane Sci. 1998, 139 (2), 211-225.

11. Zahn, R.; Voros, J.; Zambelli, T., Swelling of Electrochemically Active Polyelectrolyte Multilayers. Curr. Opinion Coll. Interface Sci. 2010, 15 (6), 427-434.

12. Flory, P. J.; Rehner, J., Statistical Mechanics of Cross-Linked Polymer Networks II Swelling. J. Chem. Phys. 1943, 11 (11), 521-526.

13. Bauer, B.; Jones, D. J.; Roziere, J.; Tchicaya, L.; Alberti, G.; Casciola, M.; Massinelli, L.; Peraio, A.; Besse, S.; Ramunni, E., Electrochemical Characterisation of Sulfonated Polyetherketone Membranes. J. New Mater. Electrochem. Systems 2000, 3 (2), 93-98.

14. Kreuer, K. D., On the Development of Proton Conducting Polymer Membranes for Hydrogen and Methanol Fuel Cells. J. Membrane Sci. 2001, 185 (1), 29-39.

15. Robertson, G. P.; Mikhailenko, S. D.; Wang, K. P.; Xing, P. X.; Guiver, M. D.; Kaliaguine, S., Casting Solvent Interactions with Sulfonated Poly(Ether Ether Ketone) During Proton Exchange Membrane Fabrication. J. Membrane Sci. 2003, 219 (1-2), 113-121.

16. Di Vona, M. L.; Licoccia, S.; Knauth, P., Organic-Inorganic Hybrid Membranes Based On Sulfonated Polyaryl-Ether-Ketones: Correlation Between Water Uptake And Electrical Conductivity. Solid State Ionics 2008, 179 (21-26), 1161-1165.

17. Jasti, A.; Prakash, S.; Shahi, V. K., Stable And Hydroxide Ion Conductive Membranes For Fuel Cell Applications: Chloromethylation and Amination of Poly(Ether Ether Ketone). J. Membrane Sci. 2013, $428,470-479$.

18. Choi, J.; Byun, Y. J.; Lee, S. Y.; Jang, J. H.; Henkensmeier, D.; Yoo, S. J.; Hong, S. A.; Kim, H. J.; Sung, Y. E.; Park, J. S., Poly(Arylene Ether Sulfone) With Tetra(Quaternary Ammonium) Moiety in the Polymer Repeating Unit for Application in Solid Alkaline Exchange Membrane Fuel Cells. Int. J. Hydrogen Energy 2014, 39 (36), 21223-21230.

19. Varcoe, J. R.; Slade, R. C. T., Prospects for Alkaline Anion-Exchange Membranes in Low Temperature Fuel Cells. Fuel Cells 2005, 5 (2), 187-200.

20. Varcoe, J. R.; Atanassov, P.; Dekel, D. R.; Herring, A. M.; Hickner, M. A.; Kohl, P. A.; Kucernak, A. R.; Mustain, W. E.; Nijmeijer, K.; Scott, K.; Xu, T. W.; Zhuang, L., Anion-Exchange Membranes in Electrochemical Energy Systems. Energy Environmental Sci. 2014, 7 (10), 3135-3191.

21. Knauth, P.; Di Vona, M. L., Sulfonated Aromatic Ionomers: Analysis of Proton Conductivity And Proton Mobility. Solid State Ionics 2012, 225, 255-259.

22. Kreuer, K. D., Ion Conducting Membranes for Fuel Cells and Other Electrochemical Devices. Chem. Mater. 2014, 26 (1), 361-380.

23. Yang, Z. G.; Zhang, J. L.; Kintner-Meyer, M. C. W.; Lu, X. C.; Choi, D. W.; Lemmon, J. P.; Liu, J., Electrochemical Energy Storage for Green Grid. Chem. Rev. 2011, 111 (5), 3577-3613.

24. Merle, G.; Wessling, M.; Nijmeijer, K., Anion Exchange Membranes for Alkaline Fuel Cells: A Review. J. Membrane Sci. 2011, 377 (1-2), 1-35.

25. Skyllas-Kazacos, M.; Rychcik, M.; Robins, R. G.; Fane, A. G.; Green, M. A., New All-Vanadium Redox Flow Cell. J. Electrochem. Soc. 1986, 133 (5), 1057-1058.

26. Li, X. F.; Zhang, H. M.; Mai, Z. S.; Zhang, H. Z.; Vankelecom, I., Ion Exchange Membranes for Vanadium Redox Flow Battery (VRB) Applications. Energy Environmental Sci. 2011, 4 (4), 1147-1160. 
27. Afonso, M. D.; De Pinho, M. N., Transport of $\mathrm{MgSO}_{4}, \mathrm{MgCl}_{2}$, and $\mathrm{Na}_{2} \mathrm{SO}_{4}$ Across an Amphoteric Nanofiltration Membrane. J. Membrane Sci. 2000, 179 (1-2), 137-154.

28. Tanaka, Y., Ion-Exchange Membrane Electrodialysis for Saline Water Desalination and its Application to Seawater Concentration. Ind. Eng. Chem. Res. 2011, 50 (12), 7494-7503.

29. Jagur-Grodzinski, J., Polymeric Materials for Fuel Cells: Concise Review Of Recent Studies. Polymers Adv. Tech. 2007, 18 (10), 785-799.

30. De Poulpiquet, A.; Ranava, D.; Monsalve, K.; Giudici-Orticoni, M. T.; Lojou, E., Biohydrogen for a New Generation of $\mathrm{H}_{2} / \mathrm{O}_{2}$ Biofuel Cells: A Sustainable Energy Perspective. ChemElectroChem 2014, 1 (11), 1724-1750.

31. Mazurenko, I.; Monsalve, K.; Infossi, P.; Giudici-Orticoni, M. T.; Topin, F.; Mano, N.; Lojou, E., Impact Of Substrate Diffusion and Enzyme Distribution in 3D-Porous Electrodes: A Combined Electrochemical And Modelling Study of a Thermostable $\mathrm{H}_{2} / \mathrm{O}_{2}$ Enzymatic Fuel Cell. Energy Environmental Sci. 2017, 10 (9), 1966-1982.

32. El Ichi-Ribault, S.; Zebda, A.; Laaroussi, A.; Reverdy-Bruas, N.; Chaussy, D.; Belgacem, M. N.; Suherman, A. L.; Cinquin, P.; Martin, D. K., Laccase-Based Biocathodes: Comparison Of Chitosan And Nafion. Anal. Chim. Acta 2016, 937, 43-52.

33. Khare, A. R.; Peppas, N. A., Swelling Deswelling of Anionic Copolymer Gels. Biomaterials 1995, 16 (7), 559-567.

34. Kreuer, K. D., The Role of Internal Pressure for the Hydration And Transport Properties Of Ionomers and Polyelectrolytes. Solid State Ionics 2013, 252, 93-101.

35. Knauth, P.; Sgreccia, E.; Di Vona, M. L., Chemomechanics of Acidic Ionomers: Hydration Isotherms And Physical Model. J. Power Sources 2014, 267, 692-699.

36. Alberti, G.; Narducci, R.; Sganappa, M., Effects of Hydrothermal/Thermal Treatments on the Water-Uptake of Nafion Membranes And Relations With Changes of Conformation, Counter-Elastic Force and Tensile Modulus of the Matrix. J. Power Sources 2008, 178 (2), 575-583.

37. Knauth, P.; Pasquini, L.; Maranesi, B.; Pelzer, K.; Polini, R.; Di Vona, M. L., Proton Mobility in Sulfonated Polyetheretherketone (SPEEK): Influence of Thermal Crosslinking and Annealing. Fuel Cells 2013, 13 (1), 79-85.

38. Drozdov, A. D.; Christiansen, J. D., Modeling The Effects of $\mathrm{pH}$ and Ionic Strength on Swelling of Anionic Polyelectrolyte Gels. Model. Simulation Mater. Sci. Eng. 2015, 23 (5), 38.

39. Drozdov, A. D.; Christiansen, J. D., Modeling the Effects of $\mathrm{pH}$ and Ionic Strength on Swelling Of Polyelectrolyte Gels. J. Chem. Phys. 2015, 142 (11), 18.

40. Xing, P. X.; Robertson, G. P.; Guiver, M. D.; Mikhailenko, S. D.; Wang, K. P.; Kaliaguine, S., Synthesis And Characterization of Sulfonated Poly(Ether Ether Ketone) for Proton Exchange Membranes. J. Membrane Sci. 2004, 229 (1-2), 95-106.

41. Jiang, R. C.; Kunz, H. R.; Fenton, J. M., Investigation of Membrane Property and Fuel Cell Behavior with Sulfonated Poly(Ether Ether Ketone) Electrolyte: Temperature and Relative Humidity Effects. J. Power Sources 2005, 150, 120-128.

42. Di Vona, M. L.; Sgreccia, E.; Licoccia, S.; Alberti, G.; Tortet, L.; Knauth, P., Analysis Of Temperature-Promoted and Solvent-Assisted Cross-Linking in Sulfonated Poly(Ether Ether Ketone) (SPEEK) Proton-Conducting Membranes. J. Phys. Chem. B 2009, 113 (21), 7505-7512.

43. Roziere, J.; Jones, D. J., Non-Fluorinated Polymer Materials for Proton Exchange Membrane Fuel Cells. Ann. Rev. Mater. Res. 2003, 33, 503-555.

44. Pasquini, L.; Ziarelli, F.; Viel, S.; Di Vona, M. L.; Knauth, P., Fluoride-Ion-Conducting Polymers: Ionic Conductivity and Fluoride Ion Diffusion Coefficient in Quaternized Polysulfones. ChemPhysChem 2015, 16 (17), 3631-3636.

45. Hickner, M. A.; Herring, A. M.; Coughlin, E. B., Anion Exchange Membranes: Current Status and Moving Forward. J. Polymer Sci. B-Polymer Phys. 2013, 51 (24), 1727-1735.

46. Di Vona, M. L.; Narducci, R.; Pasquini, L.; Pelzer, K.; Knauth, P., Anion-Conducting Ionomers: Study of Type of Functionalizing Amine and Macromolecular Cross-Linking. Int. J. Hydrogen Energy 2014, 39 (26), 14039-14049.

47. Couture, G.; Alaaeddine, A.; Boschet, F.; Ameduri, B., Polymeric Materials as Anion-Exchange Membranes for Alkaline Fuel Cells. Prog. Polymer Sci. 2011, 36 (11), 1521-1557.

48. Iojoiu, C.; Sanchez, J. Y., Polysulfone-Based Ionomers for Fuel Cell Applications. High Performance Polymers 2009, 21 (5), 673-692. 
49. Di Vona, M. L.; Pasquini, L.; Narducci, R.; Pelzer, K.; Donnadio, A.; Casciola, M.; Knauth, P., Cross-Linked Sulfonated Aromatic Ionomers Via $\mathrm{SO}_{2}$ Bridges: Conductivity Properties. J. Power Sources 2013, 243, 488-493.

50. Jones, D. J.; Roziere, J., Recent Advances in the Functionalisation of Polybenzimidazole And Polyetherketone for Fuel Cell Applications. J. Membrane Sci. 2001, 185 (1), 41-58.

51. Rujie Wang And Ming, L., Experiment And Simulation Studies Oon SPEEK PEM With Different Sulfonation Degrees. IOP Conference Series: Earth And Environmental Science 2017, 61 (1), 012026.

52. Macdonald, J. R., Impedance Spectroscopy: Emphasizing Solid Materials and Systems. Wiley: New York, 1987.

53. Mikhailenko, S. D.; Guiver, M. D.; Kaliaguine, S., Measurements of PEM Conductivity by Impedance Spectroscopy. Solid State Ionics 2008, 179 (17-18), 619-624.

54. Kortüm, G., Treatise on Electrochemistry, 2nd Edition. Elsevier: Amsterdam, New York, 1965.

55. Alberti, G.; Narducci, R.; Di Vona, M. L.; Giancola, S., More on Nafion Conductivity Decay at Temperatures Higher Than $80^{\circ} \mathrm{C}$ : Preparation and First Characterization of In-Plane Oriented Layered Morphologies. Ind. Eng. Chem. Res. 2013, 52 (31), 10418-10424.

56. Narducci, R.; Knauth, P.; Chailan, J.-F.; Di Vona, M. L., How to Improve Nafion with Tailor Made Annealing. RSC Advances 2018, 8 (48), 27268-27274.

57. Gasa, J. V.; Weiss, R. A.; Shaw, M. T., Ionic Crosslinking Of Ionomer Polymer Electrolyte Membranes Using Barium Cations. J. Membrane Sci. 2007, 304 (1-2), 173-180.

58. Narducci, R.; Di Vona, M. L.; Knauth, P., Cation-Conducting Ionomers Made By Ion Exchange of Sulfonated Poly-Ether-Ether-Ketone: Hydration, Mechanical and Thermal Properties and Ionic Conductivity. J. Membrane Sci. 2014, 465, 185-192.

59. Kreuer, K. D.; Paddison, S. J.; Spohr, E.; Schuster, M., Transport in Proton Conductors for Fuel-Cell Applications: Simulations, Elementary Reactions, and Phenomenology. Chem. Rev. 2004, 104 (10), 4637-4678.

60. Kreuer, K. D.; Rabenau, A.; Weppner, W., Vehicle Mechanism, a New Model for the Interpretation of the Conductivity of Fast Proton Conductors. Angew. Chem. Int. Ed. 1982, 21 (3), 208-209.

61. Pasquini, L.; Di Vona, M. L.; Knauth, P., Effects of Anion Substitution on Hydration, Ionic Conductivity and Mechanical Properties of Anion-Exchange Membranes. New J. Chem. 2016, 40 (4), 36713676. 
TOC Graphic

Hydration and Ionic Conductivity of Model Cation and Anion-Conducting Ionomers in Buffer Solutions (Phosphate, Acetate, Citrate)

L. Pasquini, O. Wacrenier, M. L. Di Vona, P. Knauth

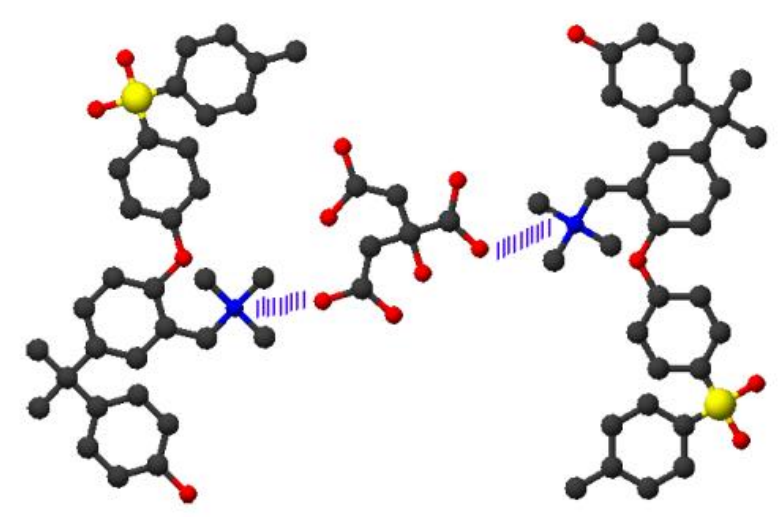

